\title{
SOME APPROACHES TO COMPERATIVE ASSESSMENT AND SELECTION OF UNMANNED AERIAL SYSTEMS
}

\author{
Mykola Kulyk $^{1}$, Valeriy Silkov ${ }^{2}$, Alexei Samkov ${ }^{3}$ \\ 1, ${ }^{3}$ National Aviation University, Kiev, Ukraine \\ ${ }^{2}$ Central Scientific-Research Institute, Kiev, Ukraine \\ E-mail:1,2eduicao@nau.edu.ua; ${ }^{3}$ sam_a2006@i.ua (corresponding author);
}

Received 19 April 2013; accepted 20 May 2013

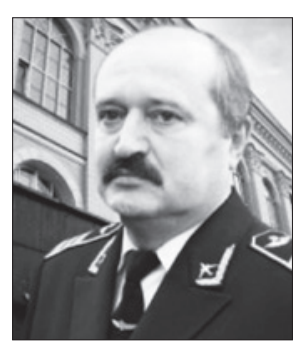

Mykola KULYK, Prof. Dr Sc., Eng.

Education: Kiev Institute of Civil Aviation Engineers, 1976. 1993 - Doctor of Science (Engineering). 1994 - Professor.

Affiliations and functions: 1997 - head of the Department of Aircraft Engines, 2008 - Rector of the National Aviation University.

Honours, awards: Honoured Person of Science and Engineering of Ukraine, winner of the State Prize of Ukraine in the area of science and technology. Present position: Rector of the National Aviation University, Ukraine.

Research interests: automatic systems of aircraft engine technical conditions.

Publications: over 200 scientific papers.

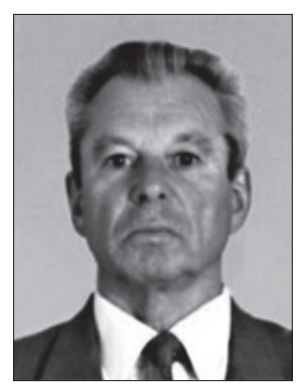

Valeriy SILKOV, Prof., Eng.

Education: Kiev Higher Educational Institution of Aviation Military Engineering. Affiliations and functions: researcher at the Central Scientific-Research Institute. Research interests: aerodynamics and dynamics of flight, UAV design.

Publications: over 170 articles.

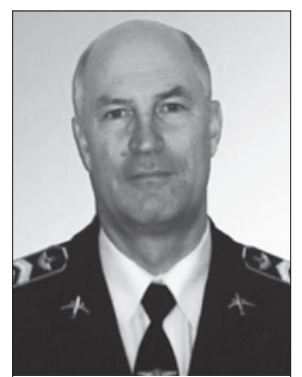

Alexei SAMKOV, Prof., Dr Sc., Eng.

Education: Kiev Higher Educational Institution of Aviation Military Engineering. Affiliations and functions: head of the Mechanics and Energy Department, National Aviation University.

Research interests: technical cybernetics and system methods of aircraft upgrading, UAV design, aerodynamics and dynamics of flight.

Publications: over 150 articles.

Abstract. Methods to solve the problems of the comparative assessment and selection of unmanned aerial systems are offered. These methods are based on the particular indicators that display the efficiency of unmanned aerial system application. An algorithm that helps to solve such problems has been developed to create a system of support and decision making and to optimise the distribution of resources.

Keywords: unmanned aerial system, method of analysing hierarchy, criteria, indicators. 


\section{Introduction}

Over the past 25 years, there has been a tremendous increase in the development of unmanned aerial vehicles. Every year thousands of samples of unmanned aerial vehicles (UAVs) are created throughout the world. The success of this rapid development of unmanned aerial vehicles can be connected with innovative projects in communications, management, navigation, computer science, artificial intellectual achievements, etc. (Gertler 2012; Goraj 2003; Harrison 2013).

One of the significant advantages of UAVs is that it is considered an aerial component and part of an unmanned aerial system (UAS). The ground component of an UAS includes technical facilities of communication and control, ground support equipment, and facilities for launching, landing, rescue, transport and storage. With this in mind, the effectiveness of the application of unmanned aerial vehicles should be assessed not only by its aerial component, but also by its ground component, in other words, the entire unmanned aerial system (Goraj 2003; Iliushko et al. 2012).

The objectives of the comparative assessment and selection of the best samples of unmanned aerial systems can appear during the design and purchase of such systems and at the stage of their application, when it is necessary to select the best to minimise cost or to guarantee a fixed result concerning some certain objectives related to UASs (Harrison 2013; Samkov, Silkov 2012).

\section{Statement of problem}

To solve the problems of comparative assessment and selection, it is first of all necessary to determine the indicators with which to make a comparison. The particular indicators offered in reference (Samkov, Silkov 2012) can be used for that. They are the following: survey capability $(W)$, cost of unmanned aerial system $(C)$, and agility $(t)$.

Modern UASs are designed on the basis of the latest achievements of science and technology and appear to be complex technical devices. One of the specific features of the problem of the comparative assessment or selection of a particular sample is the large number of possible alternative solutions based on indicators of their technical level. The technical level of UAS samples can be assessed by the level of the characteristics that determine their capabilities (Silkov 1997).

To compare several samples, expert assessment methods are most often used. Theoretical methods based on the solution of a single criterion or multi-criteria problems are also used. The main disadvantage of expert assessments is their subjectivity and dependence on the skills of the experts.

Difficulties in solving multi-criteria problems are associated with the complexity of the analysis and a large amount of computations. The most widely used methods are the simple weighing method, the ideal point method, the ELECTRA method, and the analytic hierarchy process (AHP).

The analytic hierarchy process has been most widely used lately. It was developed by American mathematician Thomas L. Saati and belongs to the multi-criteria decision-making methods. The analytic hierarchy process is based on a hierarchical or network structure of a decision-making model and priority setting of alternatives based on judgments of a decision maker. Its main advantage is the rational combination of subjective expert assessments and objective (calculated) parameters of the UAS samples that are being assessed (Saati 1990).

\section{Solution of the problem}

A four-level hierarchical structure can be used for the comparative assessment of UAS samples based on the method of hierarchy analysis. This structure can be explained with the help of figure: going from the bottom up (Fig.).

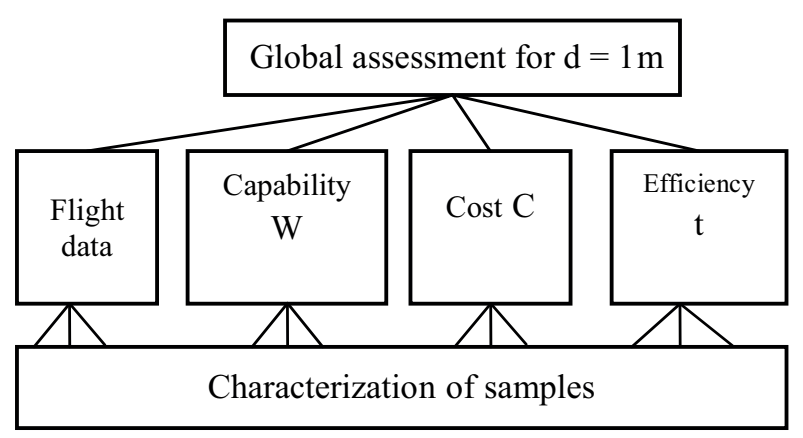

Fig. Structural diagram for determining global assessment

1. Selection of the objects of research that are similar in purpose, classification and tasks.

2. Definition of a set of parameters characterising the objects that can be compared. These objects include generalised indicators (integral quality indicators) given in reference (Mitrakhovych et al. 2012), and the parameters that characterise the technical level of the samples compared. These parameters are the following: UAV performance data, mass and geometrical data, and the payload of an UAV.

3. Selection of integral quality indicators (IQI) for the samples compared. In this problem, which is associated with the search for the specified objects, the IQIs are the following:

- IQI-1 - flight data of an UAV;

- IQI-2 - survey capability $W$;

- IQI-3 - the cost of an UAS C;

- IQI-4 - efficiency of search performed $t$.

4. The calculation of the generalised criterion of a global assessment for the systems selected. 
The analytic hierarchy process is based on the assessment of the factors that affect the lower level of the hierarchy of criteria and the indicators of higher levels of this hierarchy, taking into account all relevant parameters of the objects being compared.

The solution of the problem can be summarised in three stages:

1. Expert assessment of the importance (priority) of the parameters selected: $\mathrm{L}, \mathrm{T}, \mathrm{V}, \ldots, \mathrm{TR}$.

2. Priority assessment objects (UAS) and their characteristics.

3. Determination of global priority for the objects selected.

\subsection{Expert assessment of priority parameters determining flight characteristics of UAS}

\subsubsection{Selection of parameters to assess IQI-1}

The flight characteristics of each UAV and UAS can be determined by a set of parameters: range, duration, speed, altitude, weight of both the UAV and payload mass, capacity of the power plant and its specific fuel consumption, etc. (Silkov 1997). All of these parameters are not equal; some are more important in terms of the functions performed by UAVs, and others are less important. UAVs that search for stationary ground objects or objects that move in a selected area have the most significant parameters, which are the following: range of flight, survey of large areas, and speed of search (cruising speed), which influence the performance and efficiency of the completion of the task. The other parameters are less important even though they can include the aerodynamic characteristics of UAVs (Iliushko et al. 2012). Flight duration will obviously prevail for an UAV transponder. The definition of a set of parameters is often limited due to a lack of information about the UAVs. Some priority parameters may not be completely available and reliable for selection in order to objectively assess UAV performance (Table 1). To solve this problem, special methods of UAV sample assessment ought to be developed.

It is necessary to emphasise the importance of the take-off weight. The experience of UAS operations has proved that small units are easier to transport, and they do not require large areas and complex infrastructure. The combat capabilities of these UASs are however limited. A strong and heavy power plant is required to have the desired range of speeds and altitudes and sufficient area of survey.

The use of optoelectronic systems with good resolution and adequate range of object detection is also associated with the indices of their mass. Take-off weight is therefore an important indicator of any UAS. Increase in take-off weight affects UAV flight characteristics, however. The influence of take-off weight will therefore be assessed by the inverse of parameter P6.

Thus, the primary task of a comparative assessment of objects with a complex technical system is an expert assessment of the influence of the parameters of objects on IQI.

It is necessary to mention the next thing: if the number of parameters increases, the amount of computation increases significantly as well and the analysis gets more complicated. From this point of view, it is necessary to minimise the set of parameters. But on the other hand, it is desirable to have a more complete and comprehensive assessment of the flight characteristics of UASs. Compromise should be found in the tasks that UASs perform. UAVs searching for ground targets by scanning areas should have a large range, and UAVs performing rescue operations should have a higher flight speed. These factors can be used for the selection of parameters in table 1 .

\subsubsection{Determination of the local priorities of parameters selected for IQI-1}

The selection of the parameters that determine the flight characteristics of UASs has great importance for objective comparison. That is why experts with a large amount of experience and good intuition should be involved in this process. The experts should determine what characteristics are most important for UAVs to perform their tasks. For quantitative expert assessment involving the influence of complicated technical systems on the integral quality indicators, Saaty proposed a 9-point comparison scale of alternatives (Tab. 2) (Silkov 1997).

Table 1. Parameters of UAV performance

\begin{tabular}{|c|l|c|c|}
\hline No & \multicolumn{1}{|c|}{ Title } & Symbol & Unit of measurement \\
\hline P1 & Range & $L$ & $\mathrm{~km}$ \\
\hline P2 & Flight duration & $\mathrm{T}$ & $\mathrm{hour}$ \\
\hline P3 & Maximum speed & $V_{\text {max }}$ & $\mathrm{km} / \mathrm{h}$ \\
\hline P4 & Cruising speed & $s_{\text {cl }}$ & $\mathrm{m}$ \\
\hline P5 & Static ceiling & $1 / W_{\text {take-off }}$ & $1 / \mathrm{kg}$ \\
\hline P6 & The inverse of take-off weight & $W_{\text {fuel }}$ & $\mathrm{kg}$ \\
\hline P7 & Fuel weight & $N_{\text {take-off }}$ & horse power \\
\hline P8 & Power plant take-off parameter &
\end{tabular}


Using this table, each expert can create his own table of assessments (Tab. 3).

Table 2. Comparison scale of alternatives

\begin{tabular}{|c|l|l|}
\hline $\begin{array}{c}\text { Relative } \\
\text { importance }\end{array}$ & \multicolumn{1}{|c|}{ Determination } & \multicolumn{1}{c|}{ Explanation } \\
\hline 1 & Equal importance of indices & Equal contribution of two indices (activities) to the assessment \\
\hline 3 & Slight advantage & One of the indices has a slight advantage \\
\hline 5 & Great advantage & One of the indices has a great advantage \\
\hline 7 & Significant advantage & One of the indices is strongly superior and becomes significant \\
\hline 9 & Absolute advantage & The evidence of superiority is strongly confirmed \\
\hline $2,4,6,8$ & Opinions & Applicable in case of a compromise \\
\hline
\end{tabular}

Table 3. Matrix of priority of IQI-1 parameters

\begin{tabular}{|l|c|c|c|c|c|c|c|c|c|c|}
\hline Parameter & P1 & P 2 & P 3 & P 4 & P 5 & P 6 & P 7 & P 8 & Column 9 & Column 10 \\
\hline P 1 & 1 & 1 & 4 & 3 & 4 & 3 & 5 & 7 & 2.903 & $\boldsymbol{0 . 2 8 4}$ \\
\hline P 2 & 1.00 & 1 & 4 & 3 & 4 & 5 & 3 & 5 & 2.783 & $\boldsymbol{0 . 2 7 2}$ \\
\hline P 3 & 0.25 & 0.25 & 1 & 0.5 & 1.0 & 0.5 & 0.5 & 0.5 & 0.500 & $\boldsymbol{0 . 0 4 9}$ \\
\hline P 4 & 0.33 & 0.33 & 2.00 & 1 & 2 & 3 & 1 & 3 & 1.189 & $\boldsymbol{0} .116$ \\
\hline P 5 & 0.25 & 0.25 & 1.00 & 0.50 & 1 & 2 & 0,5 & 2 & 0.707 & $\boldsymbol{0 . 0 6 9}$ \\
\hline P 6 & 0.33 & 0.20 & 2.00 & 0.33 & 0.50 & 1 & 0,3 & 1 & 0.542 & $\boldsymbol{0 . 0 5 3}$ \\
\hline P 7 & 0.20 & 0.33 & 2.00 & 1.00 & 2.00 & 3.00 & 1 & 3 & 1.116 & $\boldsymbol{0} .109$ \\
\hline P 8 & 0.14 & 0.20 & 2.00 & 0.33 & 0.50 & 1.00 & 0.33 & 1 & 0.487 & $\boldsymbol{0 . 0 4 8}$ \\
\hline & Column1 & Column 2 & Column 3 & Column4 & Column5 & Column6 & Column7 & Column8 & 10.227 & 1.000 \\
\hline Line 9 & 3.51 & 3.57 & 18.00 & 9.67 & 15.00 & 18.50 & 11.67 & 22.50 & & \\
\hline
\end{tabular}

In this table, each row and column is a vector of a square matrix. If several experts are involved in the assessment, the indices in table 3 are agreed on by consensus, or each expert creates his own table, and the indices are given as geometric means. With the use of the following algorithm, the vector of priority parameters is calculated according to the matrix agreed on (Tab. 3). It can be seen that in accordance with the expert's assessment, preference is given to parameter P1 (range). Its weight is 0.284 . The value of parameter P2 (time of flight) is 0.272 . Parameter P8 has the least value: 0.048 . It is necessary to emphasise the importance of the correct selection of priorities, because if preference is given to an unimportant parameter, that can lead to the wrong decision and therefore the technical and economic losses. Proper selection of experts with the necessary experience, knowledge and intuition eliminates the risk of inadequate assessments. In reference (Saati 1990) the method of determining the consistency of ratings is described.

\section{Modelling results}

\subsection{Assessment of UAV priority according to flight characteristics}

Table 4 shows the vector of parameter priority to assess the importance of the options accepted by the experts for IQI-1, not taking into account their numerical values. The selection of these parameters is based on specific tasks. Moreover, UAVs are not considered. The next step is to select the object with the numerical values of the selected parameters. As an example, we have selected four UASs with known characteristics: UAV1, UAV2, UAV3 and UAV4. Their characteristics are given in table 5. At constant weight of fuel, increased take-off weight will lead to deterioration of many flight characteristics, so to assess the influence of take-off weight, the inverse of parameter P6 will be used. The data of the first column have been shown for illustration and cannot be used in the calculations. 
Table 4. Local priorities of parameters

\begin{tabular}{|c|c|c|c|c|c|c|c|c|}
\hline Parameter & P1 & P 2 & P 3 & P 4 & P 5 & P 6 & P 7 & P 8 \\
\hline Symbol & $L \mathrm{~km}$ & T hour & $V_{\max } \mathrm{km} / \mathrm{h}$ & $V_{\mathrm{crs}} \mathrm{km} / \mathrm{h}$ & $s_{\mathrm{cl}} \mathrm{m}$ & $W_{\text {take-off }} \mathrm{kg}$ & $\begin{array}{c}W_{\text {fuel }} \\
\text { kg }\end{array}$ & $\begin{array}{c}N_{\text {take-off }} \\
\text { horsepower }\end{array}$ \\
\hline Priority & 0.284 & 0.272 & 0.049 & 0.116 & 0.069 & 0.053 & 0.109 & 0.048 \\
\hline
\end{tabular}

Table 5. Flight characteristics of UAS

\begin{tabular}{|c|c|c|c|c|c|c|c|c|c|}
\hline & & P1 & P 2 & P 3 & P 4 & P 5 & P 6 & P 7 & P 8 \\
\cline { 2 - 11 } $\begin{array}{c}\text { Unmanned aerial } \\
\text { vehicle }\end{array}$ & $\begin{array}{c}\text { Take-off } \\
\text { weight } \\
\mathrm{kg}\end{array}$ & $\begin{array}{c}L \\
\mathrm{~km}\end{array}$ & $\begin{array}{c}T \\
\text { hour }\end{array}$ & $\begin{array}{c}V_{\text {max }} \\
\mathrm{km} / \mathrm{h}\end{array}$ & $\begin{array}{c}V_{\text {crs }} \\
\mathrm{km} / \mathrm{h}\end{array}$ & $\begin{array}{c}s_{\mathrm{cl}} \\
\mathrm{m}\end{array}$ & $\begin{array}{c}1 / \mathrm{W}_{\text {take-off }} \\
1 / \mathrm{kg}\end{array}$ & $\begin{array}{c}W_{\text {fuel }} \\
\mathrm{kg}\end{array}$ & $\begin{array}{c}N_{\text {take-off }} \\
\text { horsepower }\end{array}$ \\
\hline UAV 1 & 205 & 600 & 5 & 200 & 120 & 4570 & 0.00488 & 35 & 26 \\
\hline UAV 2 & 170 & 770 & 7 & 190 & 110 & 4570 & 0.00588 & 33 & 38 \\
\hline UAV 3 & 195 & 1620 & 10 & 194 & 162 & 4575 & 0.00513 & 55 & 38 \\
\hline UAV 4 & 170 & 720 & 6 & 175 & 120 & 4600 & 0.00588 & 45 & 38 \\
\hline
\end{tabular}

Table 5 allows one to identify the priorities of UAVs by taking their data into consideration. That is why a matrix should be created for each parameter. To create a matrix for parameter P1, the values of column P1 of table 5 should be used.

Table 6. Range matrix
Table 6 is formed by means of dividing each element of column P1 of table 5 by the values of UAVs (1-4) parameters that are located in the same column. As a result, we have got matrix L (size $4 \times 4$ ) given in table 6 .

\begin{tabular}{|c|c|c|c|c|c|c|}
\hline L km & UAV 1 & UAV 2 & UAV 3 & UAV 4 & Column 5 & Column 6 \\
\hline UAV 1 & 1.000 & 0.779 & 0.370 & 0.833 & 0.700 & $\mathbf{0 . 1 6 2}$ \\
\hline UAV 2 & 1.283 & 1.000 & 0.475 & 1.069 & 0.899 & $\mathbf{0 . 2 0 8}$ \\
\hline UAV 3 & 2.700 & 2.104 & 1.000 & 2.250 & 1.891 & $\mathbf{0 . 4 3 7}$ \\
\hline UAV 4 & 1.200 & 0.935 & 0.444 & 1.000 & 0.840 & $\mathbf{0 . 1 9 4}$ \\
\hline & & & & Total & 4.330 & 1.000 \\
\hline
\end{tabular}

It is important to keep in mind the influence of each parameter: if this parameter improves the characteristics of an object, its direct numerical value can be used. For example, the greater the range of an UAV is, the better its flight characteristics can be. Conversely, if an increase in the numerical value of a parameter deteriorates the characteristics of an object (e.g. increased drag Xa) its inverse value is used. For example, if $\mathrm{Xa}=1000 \mathrm{~N}$, when forming the table $1 / 1000=0.001$ is taken instead. In a similar manner, using the data of table 5, we can find the normalised vectors of flight duration, maximum and cruising speeds, static ceiling, the inverse of the take-off weight, the weight of fuel, power take-off (Tabs 7-13). The vector components in the tables are marked in boldface type. For the convenience of subsequent processing, we can distribute them in a separate table (Tab. 14), which can be used to identify the functions of each parameter.

Table 7. Flight duration matrix

\begin{tabular}{|l|l|l|l|l|l|c|}
\hline T hour & UAV1 & UAV2 & UAV3 & UAV4 & Column 5 & Column 6 \\
\hline UAV1 & 1.000 & 0.714 & 0.500 & 0.833 & 0.739 & $\mathbf{0 . 1 7 9}$ \\
\hline UAV2 & 1.400 & 1.000 & 0.700 & 1.167 & 1.034 & $\mathbf{0 . 2 5 0}$ \\
\hline UAV3 & 2.000 & 1.429 & 1.000 & 1.667 & 1.477 & $\mathbf{0 . 3 5 7}$ \\
\hline UAV4 & 1.200 & 0.857 & 0.600 & 1.000 & 0.886 & $\mathbf{0 . 2 1 4}$ \\
\hline & & & & & 4.136 & 1.000 \\
\hline
\end{tabular}


Table 8. Matrix of maximum speed

\begin{tabular}{|c|c|c|c|c|c|c|}
\hline$V_{\max } \mathrm{km} / \mathrm{h}$ & UAV1 & UAV2 & UAV3 & UAV4 & Column 5 & Column 6 \\
\hline UAV1 & 1 & 1.053 & 1.031 & 1.143 & 1.055 & $\mathbf{0 . 2 6 4}$ \\
\hline UAV2 & 0.95 & 1.000 & 0.979 & 1.086 & 1.003 & $\mathbf{0 . 2 5 0}$ \\
\hline UAV3 & 0.97 & 1.021 & 1.000 & 1.109 & 1.024 & $\mathbf{0 . 2 5 6}$ \\
\hline UAV4 & 0.875 & 0.921 & 0.902 & 1.000 & 0.923 & $\mathbf{0 . 2 3 1}$ \\
\hline & & & & Total & 4.005 & 1.000 \\
\hline
\end{tabular}

Table 9. Matrix of cruising speed

\begin{tabular}{|c|c|c|c|c|c|c|}
\hline$V_{\text {crs }} \mathrm{km} / \mathrm{h}$ & $\mathrm{UAV} 1$ & $\mathrm{UAV} 2$ & $\mathrm{UAV} 3$ & $\mathrm{UAV} 4$ & Column 5 & Column 6 \\
\hline UAV1 & 1 & 1.091 & 0.741 & 1 & 0.948 & $\boldsymbol{0 . 2 3 7}$ \\
\hline UAV2 & 0.917 & 1 & 0.679 & 0.92 & 0.869 & $\boldsymbol{0 . 2 1 7}$ \\
\hline UAV3 & 1.35 & 1.473 & 1 & 1.35 & 1.280 & $\boldsymbol{0 . 3 2 0}$ \\
\hline UAV4 & 1 & 1.091 & 0.741 & 1 & 0.948 & $\boldsymbol{0 . 2 3 7}$ \\
\hline & & & & Total & 4.045 & 1 \\
\hline
\end{tabular}

Table 10. Matrix of static ceiling

\begin{tabular}{|c|c|c|c|c|c|c|}
\hline$S_{\mathrm{cl}} \mathrm{m}$ & $\mathrm{UAV} 1$ & $\mathrm{UAV} 2$ & $\mathrm{UAV} 3$ & UAV4 & Column 5 & Column 6 \\
\hline UAV1 & 1 & 1 & 0.999 & 0.993 & 0.998 & $\mathbf{0 . 2 4 9}$ \\
\hline UAV2 & 1 & 1 & 0.999 & 0.993 & 0.998 & $\mathbf{0 . 2 4 9}$ \\
\hline UAV3 & 1.001 & 1.001 & 1.000 & 0.995 & 0.999 & $\mathbf{0 . 2 5 0}$ \\
\hline UAV4 & 1.007 & 1.007 & 1.005 & 1.000 & 1.005 & $\mathbf{0 . 2 5 1}$ \\
\hline & & & & Total & 4.000 & 1 \\
\hline
\end{tabular}

Table 11. Matrix of take-off weight

\begin{tabular}{|c|c|c|c|c|c|c|}
\hline $1 / W_{\text {take-off }}, \mathrm{kg}$ & $\mathrm{UAV} 1$ & $\mathrm{UAV} 2$ & $\mathrm{UAV} 3$ & $\mathrm{UAV} 4$ & Column 5 & Column 6 \\
\hline UAV1 & 1 & 0.829 & 0.951 & 0.829 & 0.899 & $\mathbf{0 . 2 2 4}$ \\
\hline UAV2 & 1.206 & 1.000 & 1.147 & 1.000 & 1.084 & $\mathbf{0 . 2 7 0}$ \\
\hline UAV3 & 1.051 & 0.872 & 1.000 & 0.872 & 0.945 & $\mathbf{0 . 2 3 6}$ \\
\hline UAV4 & 1.206 & 1.000 & 1.147 & 1 & 1.084 & $\mathbf{0 . 2 7 0}$ \\
\hline & & & & Total & 4.014 & 1.000 \\
\hline
\end{tabular}

Table 12. Matrix of fuel supply

\begin{tabular}{|c|c|c|c|c|c|c|}
\hline$W_{\text {fuel }} \mathrm{kg}$ & UAV1 & UAV2 & UAV3 & UAV4 & Column 5 & Column 6 \\
\hline UAV1 & 1 & 1.0606 & 0.636 & 0.778 & 0.851 & $\mathbf{0 . 2 0 8 3}$ \\
\hline UAV2 & 0.9429 & 1 & 0.600 & 0.733 & 0.803 & $\mathbf{0 . 1 9 6 4}$ \\
\hline UAV3 & 1.5714 & 1.6667 & 1.000 & 1.222 & 1.338 & $\mathbf{0 . 3 2 7 4}$ \\
\hline UAV4 & 1.2857 & 1.3636 & 0.818 & 1.000 & 1.094 & $\mathbf{0 . 2 6 7 9}$ \\
\hline & & & & Total & 4.086 & 1 \\
\hline
\end{tabular}


Table 13. Matrix of take-off power

\begin{tabular}{|c|c|c|c|c|c|c|}
\hline $\begin{array}{c}N_{\text {take-off }} \\
\text { horsepower }\end{array}$ & UAV1 & UAV2 & UAV3 & UAV4 & Column 5 & Column 6 \\
\hline UAV1 & 1 & 0.6842 & 0.684 & 0.684 & 0.752 & $\mathbf{0 . 1 8 6}$ \\
\hline UAV2 & 1.462 & 1.000 & 1.000 & 1.000 & 1.100 & $\mathbf{0 . 2 7 1}$ \\
\hline UAV3 & 1.462 & 1.000 & 1.000 & 1.000 & 1.100 & $\mathbf{0 . 2 7 1}$ \\
\hline UAV4 & 1.462 & 1.000 & 1.000 & 1.000 & 1.100 & $\mathbf{0 . 2 7 1}$ \\
\hline & & & & Total & 4.051 & 1 \\
\hline
\end{tabular}

Table 14. Local priorities of UAVs according to their parameters

\begin{tabular}{|c|c|c|c|c|c|c|c|c|}
\hline & $P 1$ & $P 2$ & $P 3$ & $P 4$ & $P 5$ & $P 6$ & $P 7$ & $P 8$ \\
\cline { 2 - 9 } & $\begin{array}{c}L \\
\mathrm{~km}\end{array}$ & $\begin{array}{c}T \\
\text { hour }\end{array}$ & $\begin{array}{c}V_{\max } \\
\mathrm{km} / \mathrm{h}\end{array}$ & $\begin{array}{c}V_{\text {crs }} \\
\mathrm{km} / \mathrm{h}\end{array}$ & $\begin{array}{c}s_{\mathrm{cl}} \\
m\end{array}$ & $\begin{array}{c}1 / \mathrm{W}_{\text {take-off }} \\
1 / \mathrm{kg}\end{array}$ & $\begin{array}{c}W_{\text {fuel, }} \\
\mathrm{kg}\end{array}$ & $\begin{array}{c}N_{\text {take-off }} \\
\text { Horse-power }\end{array}$ \\
\hline UAV1 & 0.162 & 0.179 & 0.264 & 0.237 & 0.25 & 0.224 & 0.208 & 0.186 \\
\hline UAV2 & 0.208 & 0.250 & 0.250 & 0.217 & 0.250 & 0.270 & 0.196 & 0.271 \\
\hline UAV3 & 0.437 & 0.357 & 0.256 & 0.320 & 0.250 & 0.236 & 0.327 & 0.271 \\
\hline UAV4 & 0.194 & 0.214 & 0.231 & 0.237 & 0.251 & 0.270 & 0.268 & 0.271 \\
\hline
\end{tabular}

\subsection{Calculation of the integral quality indicator} IQI-1: flight characteristics of UAS

Combining table 4 and table 14, we can determine the generalised priorities of the UAV by integral quality indicator IQI-1 (Tab. 15). In the upper part of table 15, local priority parameters and their numerical values are assessed. The generalised UAV priorities for each para- meter are assessed in the lower part, which has been obtained by multiplying the elements of the first line by the elements of the lines lying below.

The generalised priority of each UAV is calculated by summing the corresponding line. So, it equals 0.198 for UAV1, 228 for UAV2, 0.350 for UAV3 and 0.224 for UAV4. Thus the sum of all the elements must be equal to 1 .

Table 15. Generalised UAV priorities according to IQI-1

\begin{tabular}{|c|c|c|c|c|c|c|c|c|c|c|}
\hline \multicolumn{2}{|c|}{ Parameter } & $P 1$ & $P 2$ & $P 3$ & $P 4$ & $P 5$ & $P 6$ & $P 7$ & $P 8$ & \\
\hline \multicolumn{2}{|c|}{ Local priority parameters } & 0.284 & 0.272 & 0.049 & 0.116 & 0.069 & 0.053 & 0.109 & 0.048 & \\
\hline \multirow{4}{*}{$\begin{array}{l}\text { Local priorities } \\
\text { of UAV } \\
\text { according to } \\
\text { each parameter }\end{array}$} & $U A V 1$ & 0.162 & 0.179 & 0.264 & 0.237 & 0.25 & 0.224 & 0.208 & 0.186 & \\
\hline & UAV2 & 0.208 & 0.250 & 0.250 & 0.217 & 0.250 & 0.270 & 0.196 & 0.271 & \\
\hline & $U A V 3$ & 0.437 & 0.357 & 0.256 & 0.320 & 0.250 & 0.236 & 0.327 & 0.271 & \\
\hline & UAV4 & 0.194 & 0.214 & 0.231 & 0.237 & 0.251 & 0.270 & 0.268 & 0.271 & \\
\hline \multirow{4}{*}{$\begin{array}{c}\text { Generalised } \\
\text { priorities of } \\
\text { UAV according } \\
\text { to each } \\
\text { parameter }\end{array}$} & $U A V 1$ & 0.046 & 0.049 & 0.013 & 0.027 & 0.017 & 0.012 & 0.023 & 0.009 & 0.198 \\
\hline & UAV2 & 0.059 & 0.068 & 0.012 & 0.025 & 0.017 & 0.014 & 0.021 & 0.013 & 0.228 \\
\hline & UAV3 & 0.124 & 0.097 & 0.013 & 0.037 & 0.017 & 0.012 & 0.036 & 0.013 & 0.350 \\
\hline & $U A V 4$ & 0.055 & 0.058 & 0.011 & 0.027 & 0.017 & 0.014 & 0.029 & 0.013 & 0.224 \\
\hline
\end{tabular}

In this context, generalised priority can be the integral quality indicator (IQI-1) 'flight characteristics'. Since the numerical values of each flight characteristic of the UAV are assessed in accordance with this priority, the expert assessment of the importance of each parameter should be taken into account as well.

This example shows that the best UAVs in terms of flight data are UAV3, UAV2 and UAV4, which are almost identical, and the worst one is UAV1.

\subsection{Calculation of the generalised priority}

The next step is the selection of the comparative assessment and computation of integral quality indicators IQI2, IQI-3 and IQI-4 based on analogy with IQI-1. After that the final table (Tab. 16) of all integral quality indicators is formed for all systems. The generalised index of each UAV is determined as the arithmetic mean of private values. According to the results, the best UAV is determined. According to the test results, UAV3 has become the best (its IQI $=0.310)$. UAV1 has the lowest value $(0.217)$. 
Table 16. Priorities of UAVs according to their integral quality indicators

\begin{tabular}{|c|c|c|c|c|c|}
\hline \multirow{2}{*}{$\begin{array}{c}\text { Unmanned aerial } \\
\text { vehicle }\end{array}$} & \multicolumn{5}{|c|}{ Integral quality indicators } \\
\cline { 2 - 6 } & IQI-1 & IQI-2 & IQI-3 & IQI-4 & IQI average \\
\hline UAV1 & 0.196 & 0.237 & 0.213 & 0.223 & 0.217 \\
\hline UAV2 & 0.230 & 0.282 & 0.237 & 0.263 & $\mathbf{0 . 2 5 3}$ \\
\hline UAV3 & 0.349 & 0.290 & 0.284 & 0.316 & $\mathbf{0 . 3 1 0}$ \\
\hline UAV4 & 0.226 & 0.193 & 0.266 & 0.198 & $\mathbf{0 . 2 2 1}$ \\
\hline
\end{tabular}

On the basis of the proposed methodological approach, a system of support and decision making has been developed. This system allows solving the problem of selecting the best UAS samples depending on a list of tasks and their characteristics in order to minimise the cost of resources (Mitrakhovych et al. 2012). The advantages of the system of support and decision-making are the ability to make corrections to the original data of problem selection, specification of index coefficients that are being compared, and graphical interpretation of the results.

\section{Conclusion}

Methods to solve the problems of the comparative assessment and selection of unmanned aerial systems have been offered. These methods are based on the particular indicators that display the efficiency of using an unmanned aerial system. An algorithm that helps to solve such problems has been developed to create a system of support and decision making and to optimise the distribution of resources as well.

The results of the research allow us to consider the influence of characteristics on a global assessment of UASs and to make correct decisions about the selection of UASs.

\section{References}

Gertler, J. 2012. US Unmanned Aerial Systems. Congressional Research Service 7-5700 [online]: Report for Congress R42136. [cited 20 February 2013]. Available from Internet: www.crs.gov.

Goraj, Z. 2003. Civilian and military unmanned aerial vehicles - overview of European and American effort and challenges for the future, Aviation 7(1): 3-15.

Harrison, G. J. 2013. Unmanned Aircraft Systems (UAS) [online]. Manufacturing Trends. Congressional Research Service 7-5700: Report for Congress R42938 [cited 20 February 2013]. Available from Internet: www.crs.gov.

Iliushko, V.; Mitrakhovych, M.; Samkov, A., et al. 2012. Unmanned Aerial Vehicles: Methods of Approximate Calculations of the Main Parameters and Characteristics. Kiev: Press of the Air Force Research Institute of Ukraine. 302 p.

Mitrakhovych, M.; Samkov, A.; Silkov, V., et al. 2012. Unmanned Aerial Systems. Methods of Comparative Assessment of Their Combat Capabilities. Kiev: Press of the Air Force Research Institute of Ukraine. 288 p.

Saati, T. L. 1990. Multi-Criteria Decision Making: The Analytical Hierarchy Process. New York: McGraw Hill. 219 p.

Samkov, A.; Silkov, V. 2012. Some particular indices of effectiveness of unmanned aerial vehicle application, Aviation 16(3): 57-62.

http://dx.doi.org/10.3846/16487788.2012.732302

Silkov, V. 1997. Aircraft Flight Dynamics. Kiev: Press of Kiev International University of Civil Aviation. 425 p. 